\title{
Identification of novel mutations and phenotype in the steroid resistant nephrotic syndrome gene NUP93: a case report
}

\author{
Ibrahim Sandokji', Jonathan Marquez², Weizhen $\mathrm{Ji}^{2}$, Cynthia A. Zerillo², Monica Konstantino², Saquib A. Lakhani², \\ Mustafa K. Khokha ${ }^{2}$ and Jillian K. Warejko ${ }^{1^{*}}$ (i)
}

\begin{abstract}
Background: Monogenic mutations may be a significant cause of steroid-resistant nephrotic syndrome. NUP93 is a gene previously reported to cause isolated steroid-resistant nephrotic syndrome.

Case presentation: Here we describe a case of recessive, syndromic, steroid-resistant nephrotic syndrome caused by NUP93 mutation.
\end{abstract}

Conclusions: NUP93 may convey a phenotype that has not only SRNS, but also other syndromic features.

Keywords: Steroid-resistant nephrotic syndrome, Focal segmental glomerulosclerosis, Whole exome sequencing, Genetics, Inherited diseases

\section{Background}

Steroid therapy is a mainstay of treatment for nephrotic syndrome. However, in $15-20 \%$, there is no response to steroid therapy [1], increasing the risk of developing end-stage renal disease (ESRD) and requiring renal replacement therapies during the first two decades of life [2]. In 11-30\% of steroid-resistant nephrotic syndrome (SRNS), a known gene mutation can be detected [3]. NUP93 is a widely expressed gene that encodes a highly conserved nuclear pore protein. Knockdown of NUP93 leads to inhibition of podocytes proliferation by impairing SMAD signaling resulting in focal segmental glomerulosclerosis (FSGS). Mutations of NUP93 have been shown to cause non-syndromic autosomal recessive FSGS, that can progress to ESRD within ten years $[4,5]$. Here we describe a case of novel NUP93 mutations in a child with a syndromic SRNS phenotype.

\footnotetext{
* Correspondence: jillian.warejko@yale.edu

'Department of Pediatrics, Section of Nephrology, Yale University School of Medicine, 333 Cedar St., PO Box 208064, New Haven, CT 06520-8064, USA Full list of author information is available at the end of the article
}

\section{Case presentation}

A 5-year-old nonconsanguineous girl of African American and Hispanic origin presented with nephrotic syndrome, including nephrotic-range proteinuria (UPC of $>29 \mathrm{mg} / \mathrm{mg}$ ), edema, and hypoalbuminemia. Her initial serum creatinine was $654 \mu \mathrm{mol} / \mathrm{L}$. Other pertinent laboratory evaluation at time of presentation included albumin of $19 \mathrm{~g} / \mathrm{L}, \mathrm{BUN}$ of $38 \mathrm{mmol} / \mathrm{L}$, potassium of $6 \mathrm{mmol} / \mathrm{L}$, bicarbonate of $12 \mathrm{mmol} / \mathrm{L}$, calcium of $1.7 \mathrm{mmol} / \mathrm{L}$, phosphorus of $2.5 \mathrm{mmol} / \mathrm{L}$, and parathyroid hormone of 396 $\mathrm{ng} / \mathrm{L}$. She was oligoanuric and hemodialysis was initiated. An ultrasound of her kidneys showed diffuse echogenicity and loss of corticomedullary differentiation (Fig. 1). Her history was significant for developmental delay and short stature. Her proteinuria presented in the setting of a previous respiratory illness but was not investigated. She has a normal-looking face and without dysmorphic features which was confirmed by the hospital's geneticist. An ophthalmological examination did not show cataract or retinal changes. She has normal looking ears and exhibited normal hearing. She was normocephalic and did not have an exam consistent with GAMOS and no uro-genital anomalies were 

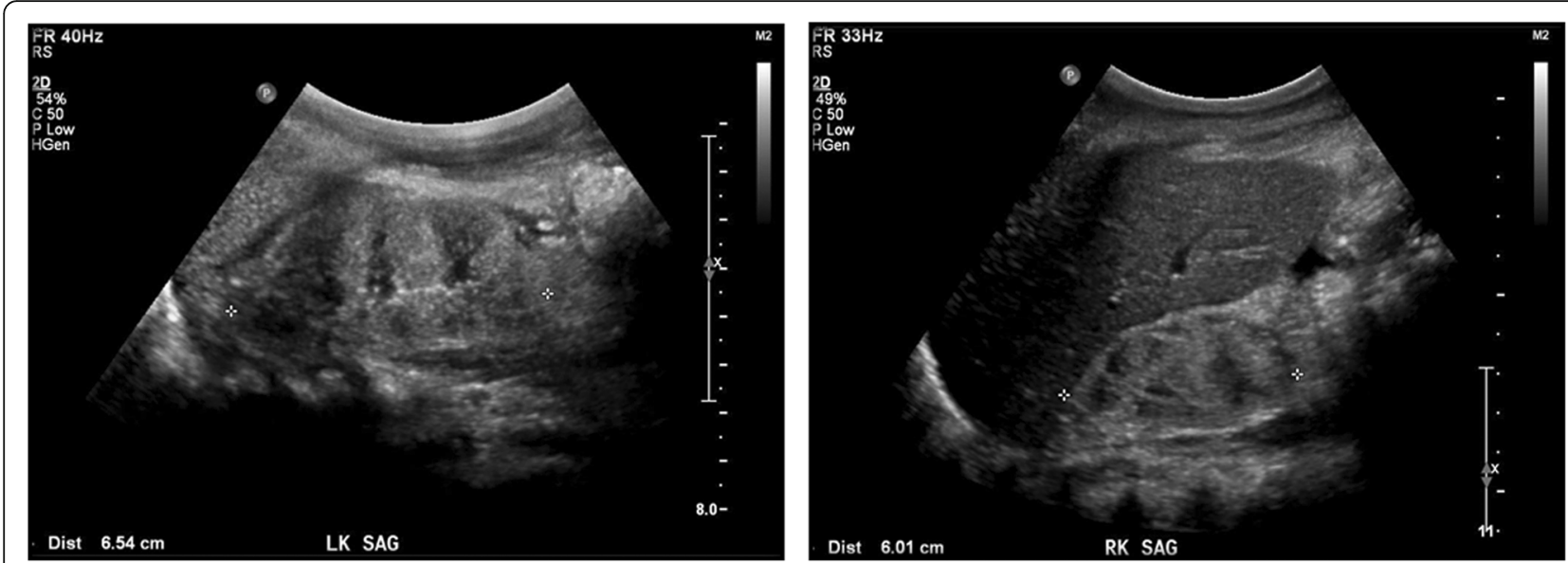

Fig. 1 Renal ultrasound at presentation. The patient's kidneys were notable for small size, diffuse echogenicity and loss of corticomedullary differentiation. Average kidney size for 5 -year-old children is $8 \mathrm{~cm}$, however she was small for age, and for a $90 \mathrm{~cm}$ tall child the average kidney size is $7.1 \mathrm{~cm}$ with $95 \%$ prediction limits of 5.8 to $8.3 \mathrm{~cm}$. The ultrasound was performed at the time she was anuric, hence the renal pelvis appears to be collapsed

identified. She had normal birth history, and her family history was not significant for renal, cardiac or neurological development problems.

In addition to her kidney involvement, she had developmental delays with autistic features; including delays in expressive language, fine motor, social communication and repetitive hand movements. She had expressive, receptive, and pragmatic language difficulties with a low score in the auditory comprehension subtest of the Preschool Language Scales. Additionally, while awaiting renal transplant, she had two episodes of heart failure requiring inotropic support after having adequate dialysis for more than a month. She had severely elevated B-type natriuretic peptide (BNP) levels ( $>70$, $000 \mathrm{pg} / \mathrm{mL}$ ) and her echocardiogram showed systolic and diastolic dysfunction (ejection fraction as low as 35\%) and dilated cardiomyopathy features (Fig. 2). After receiving aggressive nutritional support and blood pressure management, her cardiac function improved with ejection fractions range in $40-50 \%$. She received a living related kidney transplant without recurrence of cardiac symptoms, and normal cardiac structures on echocardiograms with ejection fractions $>60 \%$. Given that we know NUP93

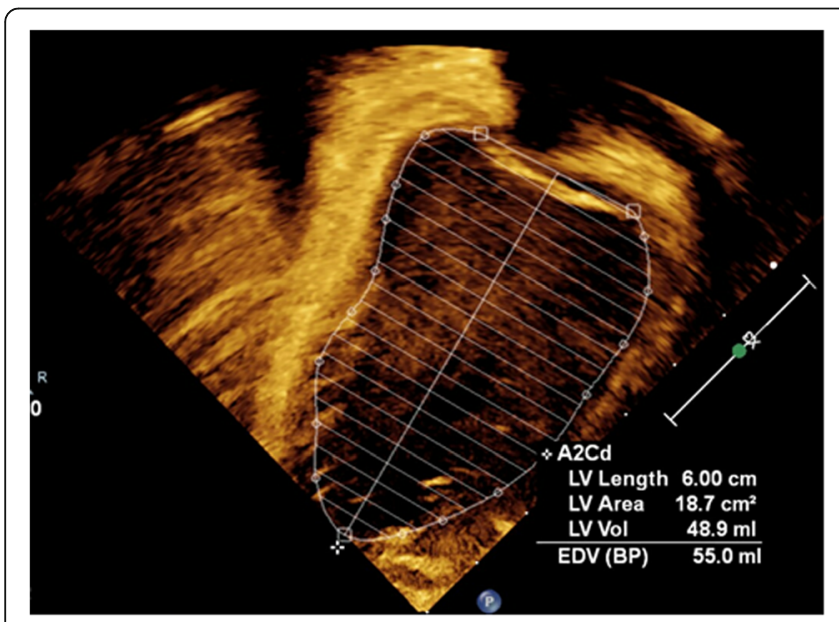

End Diastole

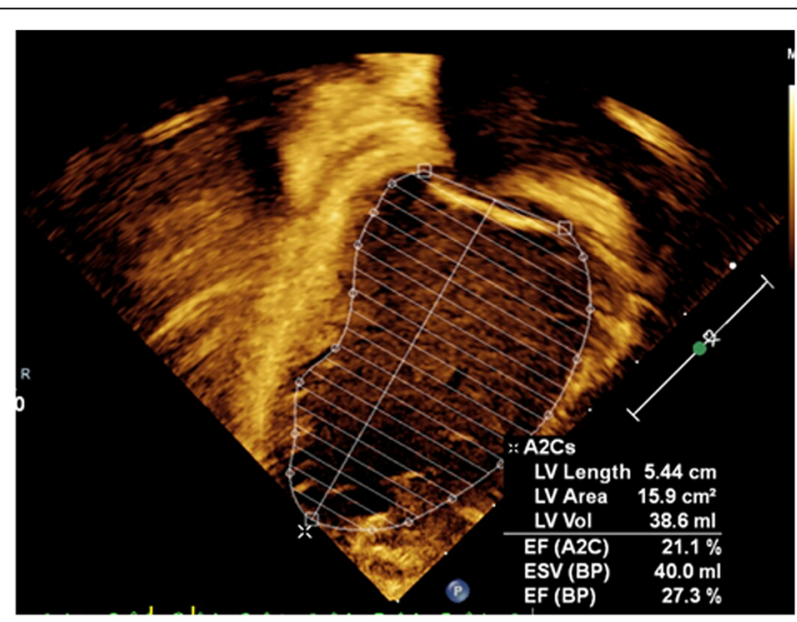

End Systole

Fig. 2 Patient echocardiogram. An apical, left two-chamber view shows moderately dilated left ventricle, mild concentric left ventricular hypertrophy and severely reduced systolic function. Left ventricular end diastolic diameter Z score 5.59 by M-mode and end-diastolic volume by $5 / 6$ area length method is Z score 4.98. left ventricular dp/dt of 1398. There is also a LV diastolic dysfunction with fusion of E and A waves of inflow doppler pattern. There is moderate to severe mitral valve regurgitation and mild to moderate tricuspid regurgitation. The aortic and pulmonary valves are trivially regurgitant. There is no pericardial effusion 


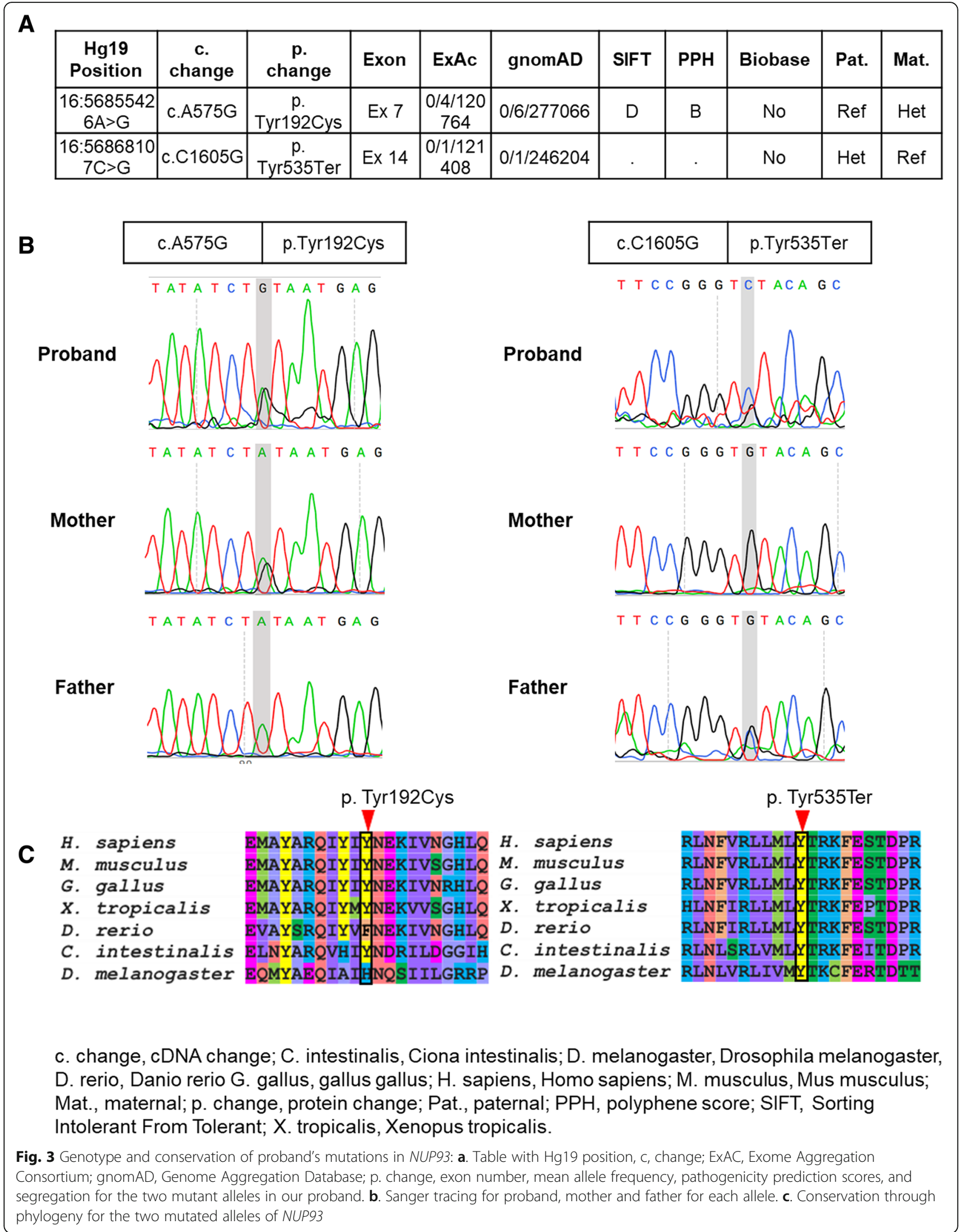


does localize to cilia in Xenopus during cardiac development, we cannot exclude there may have been a contribution of the patient's mutations to this phenotype. After her kidney transplant, she did not have recurrence of her nephrotic syndrome, but had a brief period of proteinuria (maximum UPC of 3.6) that was monitored closely and resolved within one week.

Given her presentation of likely hereditary nephrotic syndrome, we sent clinical whole exome sequencing (WES). WES demonstrated a compound heterozygous mutations in NUP93; a maternal missense variant (chr16:56855426 A > G) c.A575G, p. Tyr192Cys and a paternal nonsense variant (chr16:56868107 C> G) c.C1605G, p. Tyr535Ter (Fig. 3). Both variants are extremely rare, only 6 alleles of p.Tyr192Cys and 1 allele of p.Tyr535Ter have been reported previously in a large population database (gnomAD) with over 246,000 chromosomes, with a higher frequency of p.Tyr535Ter in African population ( 1 in $16,256)$. These allele frequencies are $<0.1 \%$, which we have previously used as a cut off for filtering potentially pathogenic alleles [6]. The locations of the two variants are in the $\alpha$ helical domain of the NUP93 protein, as are some of the previously reported pathogenic mutations in Braun, et al. [5]. The tyrosine at position 192 is conserved through phylogeny, and the missense variant Tyr192Cys had high impact prediction scores for deleteriousness by CADD or SIFT. The nonsense variant p. Tyr535Ter likely results in defective protein structure either through truncation or nonsense-mediated mRNA decay. Additional analysis of her WES did not identify mutations related to cardiomyopathy.

\section{Discussion and conclusions}

We identified novel compound heterozygous mutations of NUP93 gene using WES in a patient with nephrotic syndrome progressing to ESRD in the first decade of life. Fourteen patients were reported to have NUP93 mutations associated with SRNS [4-6]. Nup93 variants were first reported in 9 families with isolated SRNS [5]. Rapid progression into ESRD was also observed in a subsequent case series of genetic SRNS due to NUP93 mutations $[3,4,6]$.

As part of the nuclear pore complex, NUP93 protein functions in transport between the cytoplasm and nucleus and was shown to have a significant role in the SMAD signaling pathway in Drosophila [7]. Braun et al. studied the role of NUP93 in immortalized human podocytes, and demonstrated a critical role for NUP93 in bone morphogenetic protein 7 (BMP7)-dependent SMAD signaling, a novel pathway for SRNS [5]. This interaction supports the role of BMP7 in renal response to injuries and development of chronic kidney changes. The defect of SMAD signaling was shown in all NUP93 knock out cells and resulted in reduced podocyte proliferation. In addition, Nup93 is essential for cilia and cardiac development in Xenopus and may play a role at the cilium base that is independent of its role in the nuclear pore [8]. Loss of cilia can cause a cardiomyopathy in mice suggesting a potential pathogenic mechanism for the cardiomyopathy in our patient [9]. Another nucleoporin mutation, NUP107, was reported in one child with dilated cardiomyopathy indicating the potential role of ciliopathies in cardiac dysfunction [10]. Interestingly, despite the ubiquitous role of nuclear pore proteins, variants of Nup 93 appear to give tissue specific phenotypes.

This case demonstrates a novel phenotype of extrarenal manifestations that were not previously described in individuals with NUP93 mutation. Unlike prior reported cases of NUP93 mutations, our patient had neurological and cardiac involvement including significant developmental delay and cardiomyopathy.

Our patient's genetic testing was negative for genes that cause Galloway-Mowat syndrome (GAMOS) though the constellation of glomerulopathy, central nervous system involvement might suggest this syndrome which was reported in other nucleoporin mutations [10-12].

When compared to idiopathic SRNS, genetic causes of SRNS usually do not recur after transplant hence these patients do not require higher immunosuppression as in idiopathic forms of SRNS $[3,6]$. In a case series of four patients of Czech and Slovak patients with SRNS, one patient had recurrence of nephrotic syndrome 20 months after transplantation [4].

We describe novel mutations in the NUP93 gene resulting in a syndromic phenotype with neurologic and cardiac features. It remains unclear if the NUP93 variant contributed to her cardiomyopathy, as this gene has also been described as localizing to cilia as well as the nucleoporin. WES is the ideal test for patients with SRNS as a conclusive molecular diagnosis does influence therapeutic choices.

\section{Abbreviations}

BMP7: Bone morphogenetic protein 7; ESRD: End-stage renal disease; FSGS: Focal segmental glomerulosclerosis; SRNS: Steroid-resistant nephrotic syndrome; WES: Whole exome sequencing

\section{Acknowledgements \\ The authors thank the patients and families who are the inspiration for this report.}

\section{Authors' contributions}

IS and JKW analyzed and interpreted the patient data. JM, WJ, CAZ, MK, SAL and MKK performed the whole exome sequencing and interpreted the data. All authors read and approved the final manuscript.

\section{Funding}

This work was supported by the NIH/NHLBI (R01HL124402) in the design of the study and collection, analysis, and interpretation of data and in writing the manuscript. MKK was a Mallinckrodt Scholar. 


\section{Availability of data and materials}

Data sharing is not applicable to this article as no datasets were generated or analysed during the current study.

\section{Ethics approval and consent to participate}

Not applicable.

\section{Consent for publication}

Written informed consent was obtained from the legal guardian of the patient for publication of this Case Report and any accompanying images. A copy of the written consent is available for review by the Editor of this journal. Written and informed consent was obtained from parents for participation in Dr. Khoka and Lakhani's study, and the publication of the data generated, as well as the participation and publication of the data generated for the child.

\section{Competing interests}

No competing financial or non-financial interests exist.

\section{Author details}

${ }^{1}$ Department of Pediatrics, Section of Nephrology, Yale University School of Medicine, 333 Cedar St., PO Box 208064, New Haven, CT 06520-8064, USA.

${ }^{2}$ Pediatric Genomics Discovery Program, Department of Pediatrics and Genetics, Yale University School of Medicine, New Haven, CT, USA.

Received: 7 January 2019 Accepted: 8 July 2019

Published online: 17 July 2019

\section{References}

1. Primary nephrotic syndrome in children. Clinical significance of histopathologic variants of minimal change and of diffuse mesangial hypercellularity. Kidney International. 1981;20(6):765-71.

2. Mekahli D, Liutkus A, Ranchin B, Yu A, Bessenay L, Girardin E, Van DammeLombaerts R, Palcoux JB, Cachat F, Lavocat MP, et al. Long-term outcome of idiopathic steroid-resistant nephrotic syndrome: a multicenter study. Pediatr Nephrol. 2009;24(8):1525-32.

3. Bierzynska A, McCarthy HJ, Soderquest K, Sen ES, Colby E, Ding WY, Nabhan MM, Kerecuk L, Hegde S, Hughes D, et al. Genomic and clinical profiling of a national nephrotic syndrome cohort advocates a precision medicine approach to disease management. Kidney Int. 2017; 91(4):937-47

4. Bezdicka M, Stolbova S, Seeman T, Cinek O, Malina M, Simankova N, Pruhova S, Zieg J. Genetic diagnosis of steroid-resistant nephrotic syndrome in a longitudinal collection of Czech and Slovak patients: a high proportion of causative variants in NUP93. Pediatr Nephrol. 2018; 33(8):1347-63.

5. Braun DA, Sadowski CE, Kohl S, Lovric S, Astrinidis SA, Pabst WL, Gee HY Ashraf S, Lawson JA, Shril S, et al. Mutations in nuclear pore genes NUP93, NUP205 and XPO5 cause steroid-resistant nephrotic syndrome. Nat Genet. 2016;48(4):457-65.

6. Warejko JK, Tan W, Daga A, Schapiro D, Lawson JA, Shril S, Lovric S, Ashraf S, Rao J, Hermle T, et al. Whole exome sequencing of patients with steroid-resistant nephrotic syndrome. Clin J Am Soc Nephrol. 2018; 13(1):53-62

7. Chen $\mathrm{X}, \mathrm{Xu}$ L. Specific nucleoporin requirement for Smad nuclear translocation. Mol Cell Biol. 2010;30(16):4022-34

8. Del Viso F, Huang F, Myers J, Chalfant M, Zhang Y, Reza N, Bewersdorf J, Lusk CP. Khokha MK. Congenital heart disease genetics uncovers contextdependent organization and function of nucleoporins at cilia. Dev Cell. 2016;38(5):478-92.

9. Slough J, Cooney L, Brueckner M. Monocilia in the embryonic mouse heart suggest a direct role for cilia in cardiac morphogenesis. Dev Dyn. 2008; 237(9):2304-14

10. Braun DA, Lovric S, Schapiro D, Schneider R, Marquez J, Asif M, Hussain MS, Daga A, Widmeier E, Rao J, et al. Mutations in multiple components of the nuclear pore complex cause nephrotic syndrome. J Clin Invest. 2018;128(10): 4313-28.

11. Rosti RO, Sotak BN, Bielas SL, Bhat G, Silhavy JL, Aslanger AD, Altunoglu $U$, Bilge I, Tasdemir M, Yzaguirrem AD, et al. Homozygous mutation in NUP107 leads to microcephaly with steroid-resistant nephrotic condition similar to Galloway-Mowat syndrome. J Med Genet. 2017; 54(6):399-403.

12. Fujita A, Tsukaguchi $H$, Koshimizu E, Nakazato $H$, Itoh K, Kuraoka S, Komohara Y, Shiina M, Nakamura S, Kitajima M, et al. Homozygous splicing mutation in NUP133 causes Galloway-Mowat syndrome. Ann Neurol. 2018; 84(6):814-28

\section{Publisher's Note}

Springer Nature remains neutral with regard to jurisdictional claims in published maps and institutional affiliations.

\section{Ready to submit your research? Choose BMC and benefit from:}

- fast, convenient online submission

- thorough peer review by experienced researchers in your field

- rapid publication on acceptance

- support for research data, including large and complex data types

- gold Open Access which fosters wider collaboration and increased citations

- maximum visibility for your research: over $100 \mathrm{M}$ website views per year

At BMC, research is always in progress.

Learn more biomedcentral.com/submissions 